\title{
The effect of rapid sosio-economic develop- ment on the frequency of leprosy in a population
}

\author{
K SAIKAWA \\ National Leprosarium, Okinawa Airakuen, Okinawa, Japan
}

Leprosy control in Japan marked its beginning in 1909 when the government decided to open leprosaria to adopt segregation as its basic policy for leprosy control and this policy has been practiced ever since for the past 70 years though segregation is no longer compulsory now. As of 1980, Japan has 9,502 registered leprosy patients (prevalence rate of $0.82 / 10,000$ ) (see Table 1 ). Out of this number 8,540 (90\%) are in-patients.

Out of 110 million total population in Japan there were only 37 new cases detected in 1980 (incidence rate $0.031 / 100,000$ ), which indicates a marked decline in the incidence of leprosy in the past 25 years, now mere one fifteenth of that in 1955 when there were 433 new cases (incidence rate $0.48 / 100,000$ ). The similar trend of declining incidence rate has been observed in Okinawa, currently the only remaining endemic region of leprosy in Japan. The incidence rate in Okinawa alone in 1967 was 18.02/ 100,000 whereas in 1980 it was $1.71 / 100,000$, being reduced to one tenth within 13 years.

Table 1: Leprosy Epidemiological Situation in Japan, Okinawa and Taiwan

\begin{tabular}{|c|c|c|c|c|}
\hline & Japan & $\begin{array}{l}\text { Mainland } \\
\text { Japan }\end{array}$ & Okinawa & Taiwan \\
\hline $\begin{array}{l}\text { No. of Leprosy Patients } \\
\text { Prevalence Rate/10,000 }\end{array}$ & $\begin{array}{l}9,502 \\
(0.82) \\
\end{array}$ & $\begin{array}{l}8,019 \\
(0.72) \\
\end{array}$ & $\begin{array}{l}1,483 \\
(13.40) \\
\end{array}$ & $\begin{array}{l}4,396 \\
(2.47) \\
\end{array}$ \\
\hline $\begin{array}{c}\text { No. of Out-patients } \\
(\%)\end{array}$ & $\begin{array}{r}962 \\
(10.0) \\
\end{array}$ & $\begin{array}{c}449 \\
(5.6) \\
\end{array}$ & $\begin{array}{c}513 \\
(34.6) \\
\end{array}$ & $\begin{array}{l}3,542 \\
(80.6)\end{array}$ \\
\hline $\begin{array}{c}\text { No. of In-patients } \\
(8)\end{array}$ & $\begin{array}{l}8,540 \\
(90.0)\end{array}$ & $\begin{array}{l}8,570 \\
(94.4)\end{array}$ & $\begin{array}{r}970 \\
(65.4)\end{array}$ & $\begin{array}{r}854 \\
(19.4)\end{array}$ \\
\hline $\begin{array}{l}\text { No. of New Patients } \\
\text { Incidence Rate/100,000 }\end{array}$ & $\begin{array}{r}37 \\
(0.030) \\
\end{array}$ & $\begin{array}{c}18 \\
(0.015) \\
\end{array}$ & $\begin{array}{c}19 \\
(1.710) \\
\end{array}$ & $\begin{array}{r}54 \\
(0.300) \\
\end{array}$ \\
\hline $\begin{array}{l}\text { Population } \\
\text { (Million) }\end{array}$ & 111 & 110 & 1.1 & 17 \\
\hline
\end{tabular}


The mainland Japan, excluding Okinawa, Okinawa and Taiwan have concurrently made a rather rapid socio-economic development in recent years, and at the same time, in all these three regions a marked decline in the rates of incidence of leprosy has been observed. The possible co-relative factors between socio-economic development of these three regions and the decline in their incidence rates of leprosy will be discussed hereunder.

\section{Leprosy in Japan}

A survey which took place in 1900 revealed that in Japan including Okinawa there were 30,359 leprosy patients. The prevalence rate of the total population and that of the in-patients are shown in Figure 1. The figure indicates that as the number of in-patients

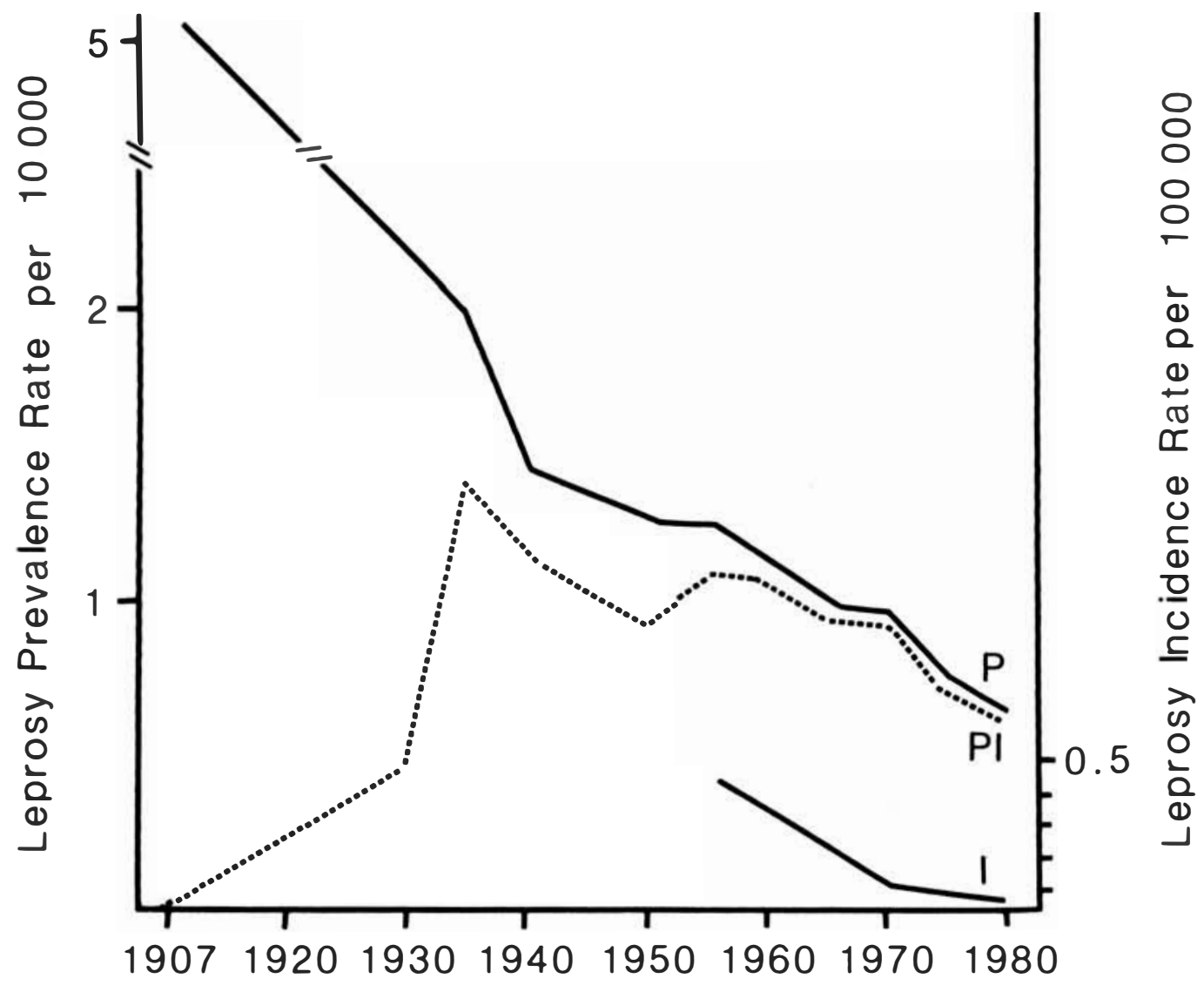

Figure 1. To show the relationship between Prevalence Rate, Incidence Rate and In-patient Rate per population in Japan. P:Prevalence Rate, I:Incidence Rate, PI:In-patient Rate. 
increased the total prevalence rate decreased. By 1935 nearly 91\% of all leprosy patients were segregated in leprosaria and this probably contributed to reduce the possibility of transmission of the disease among the general public. This large scale segregation was made only possible when the government decided to allocate a huge amount of budget for leprosy control. The government budget allocated for leprosy work in Japan in 1980 was US\$110 million in total, which means US\$13,000 per in-patient per year, but most of this is a social welfare cost of arrested cases of leprosy and not the direct cost of medical treatment of active cases of leprosy.

The incidence rate, as shown in Figure 2, has declined considerably during this period. The decline started around 1960, and during the decade between 1969 and 1970 it marked the decline of $70 \%$ at the maximum.

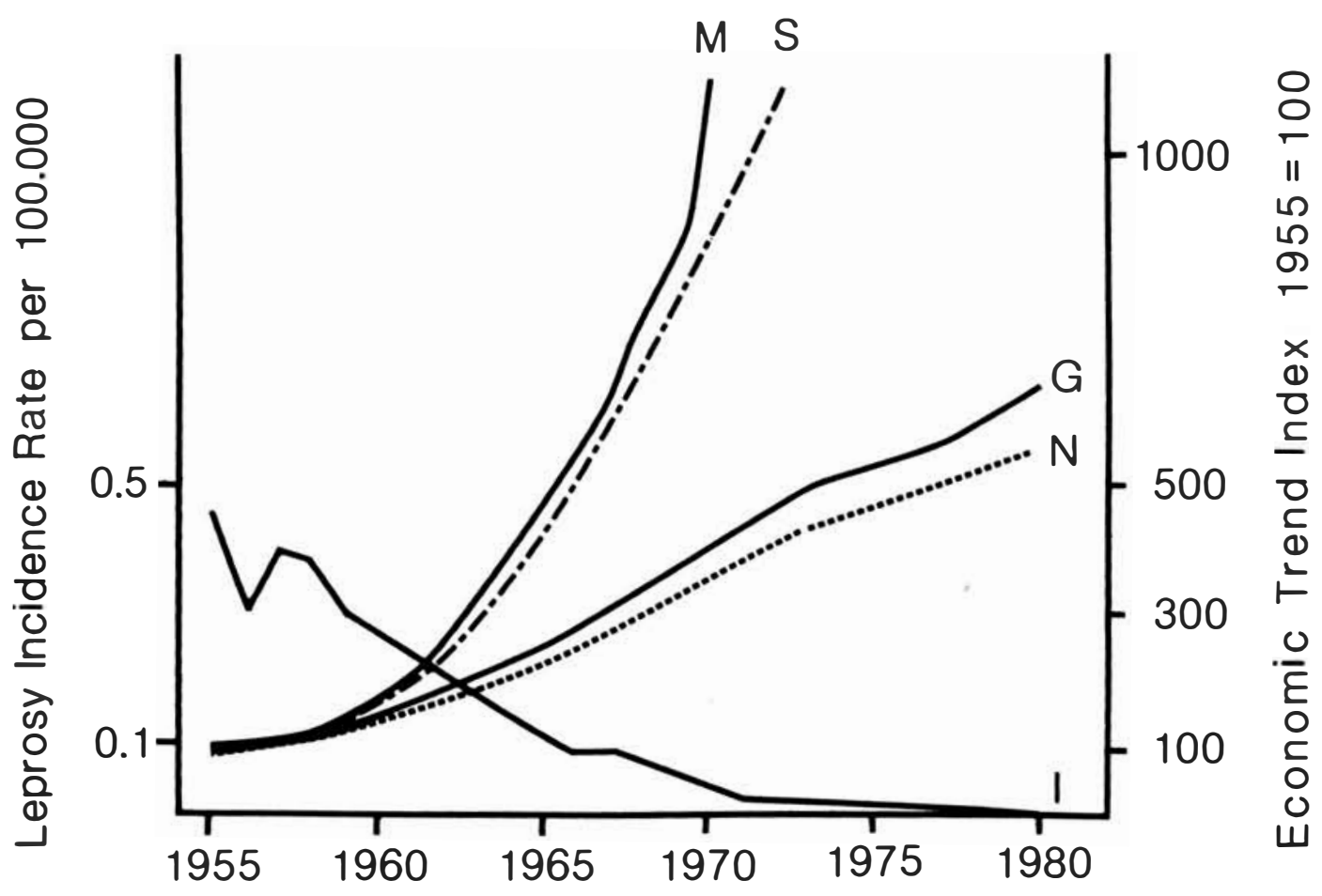

Fiqure 2. To show the relationship between trend of Economic and Incidence Rate in Japan. G:GNP, N:National Income, M:National Medical Care Incurance, S:Expenditure on Social Security, I: Leprosy Incidence Rate 


\section{SOCIO-ECONOMIC CONDITION}

Japanese economy made a rapid recovery and growth in the post World War II period. Per capita National Income in 1945 was only one half of that in 1935, but in 1955 it surpassed that level. Figure 2 shows the trends of GNP, National budget, per capita National Income, Expenditure for National Medical Care, and Expenditure for Social Security Welfare. It is evident that high annual increases of these indices were all made before 1970. In other words the notable achievements in economic recovery and development took place prior to 1970 when the incidence rates of leprosy came close to the lowest level.

The considerable socio-economic development of post-war Japan has enabled the government to improve its medical services, public health program, environment sanitation etc., and also the growth in National Income made it possible for individual citizens of Japan to improve their overall standard of living, including nutrition and housing. In the following chapter the possible relationship between the rapid socio-economic development and the decline in incidence rate of leprosy will be discussed taking examples from Okinawa, because these points will be better illustrated in Okinawa, with the total population of only one million rather than the whole of Japan with 110 million population.

\section{Leprosy in Okinawa}

When the World War II ended in 1945, Okinawa came under the rule of the United States, administratively separated from the rest of Japan, until it was reverted to Japanese authorities in 1972. Okinawa, which is sometimes called "Ryukyu Islands" consists of over 40 islands which lie between Taiwan in the south and Kyushu of Japan in the north and its climate is subtropical. Leprosy control work started in the mainland Japan in 1909, but in Okinawa it had to wait another 30 years until 1938. It was 11.6/ 10,000 in 1900 but in 40 years it more than doubled and reached 25.3/10,000 in 1940. This is a clear contrast to the steady decline in prevalence rate achieved in the mainland Japan where rather strict segregation policy was carried out. This probably support the idea that leprosy in the pre-chemotherapy period can only be tackled by segregation method and without it there may be an increase in prevalence rate.

Since the establishment of leprosaria in 1938 Okinawa did see the decline in its prevalence rate. However, near the end of the World War II in 1945, Okinawa suffered the total devastations when leprosaria were destroyed and all the patients were scattered. A survey conducted by the United States Civilian Administration (USCAR) at that time estimated that nearly 800 patients were still left in the communities at large.

In 1962 according to the new leprosy prevention law USCAR and Ryukyu Government jointly started out-patient treatment for those 
patients left in the community. Since then the number of patients coming for out-patient treatment increased until it reached its peak in 1967 when the incidence rate or case-detection rate marked $1.8 / 100,000$ (Figure 3).

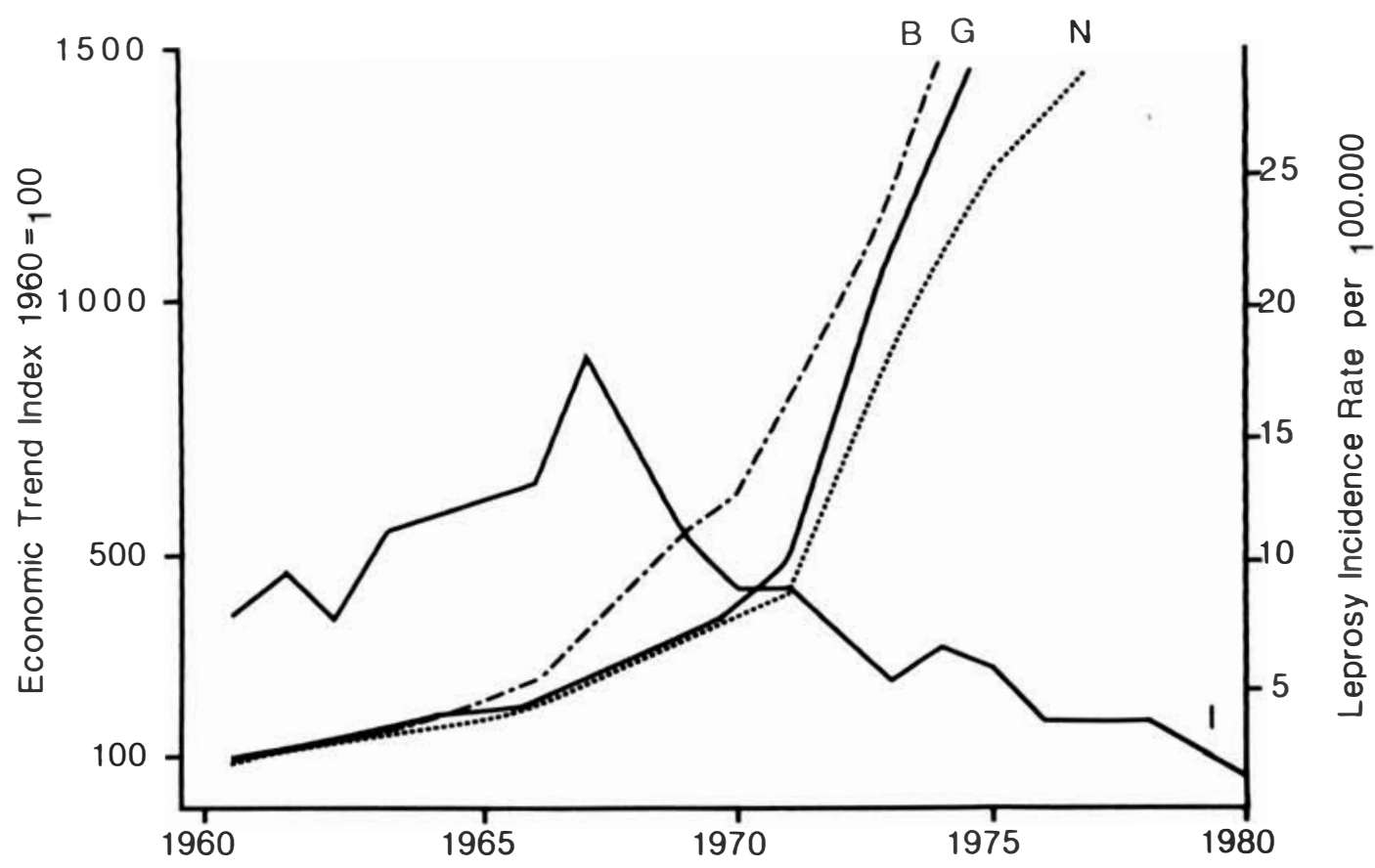

Figure 3. To show the relationship between trend of Economic and Incidence Rate in Okinawa. G:GNP, N:National Income, B:Local Government Budget, I:Incidence Rate

Okinawa started its segregation policy of leprosy cases 30 years behind the mainland Japan, but through chemotherapy of both in- and out-patients it treated up to $92 \%$ of known patients thus apparently succeeded in minimizing the danger of transmission of the disease in the community.

\section{SOCIO-ECONOMIC CONDITION IN OKINAWA}

Socio-economic conditions recovered in 1955 when the per capita National Income reached its 1935 pre-war level of US\$146. Figure 3 shows rapid economic development after 1960, in which one will note that remarkable growth in GNP, National Income and Local 
Government Budget took place since 1970.

Now few aspects of socio-economic development which may have some influence on decline of leprosy incidence will be discussed.

\section{Housing}

Personal expenditure on housing increased as the National Income increased. (Table 2)

\section{a) Building New Houses}

Table 2 shows the annual number of new houses erected in

okinawa. In 1960 a total of 3,846 were built (Indexed 100) and in 1970 the index rose to 400 indicating considerable improvement in housing situations after 1970.

b) Personal Expenditure on Housing

$5.5 \%$ of personal expenditure was spent on housing in 1955 but in 1970 it reached 13.4\%, the highest so far, this too indicating that from 1970 onward the housing situations improved.

c) Housing Difficulties

Housing difficulties is expressed in terms of occupation density: meaning people residing in small, overcrowded lodging. Housing difficulty was $65.6 \%$ in 1955 but it was reduced to $22 \%$ in 1970 and in 1978 it came down to as low as 5.6\%, indicating that housing difficulties had been almost removed.

Table 2. The Trend of Housing

\begin{tabular}{lcccccc}
\hline & 1955 & 1960 & 1965 & 1970 & 1975 & 1980 \\
\hline Building New House & - & 3846 & 6730 & 15384 & 18626 & 14999 \\
\hline $\begin{array}{l}\text { Personal Expenditure } \\
\text { on Housing }(8)\end{array}$ & 5.5 & 6.2 & 7.8 & 13.4 & 11.4 & 11.5 \\
\hline $\begin{array}{l}\text { Housing } \\
\text { Difficulty }(8)\end{array}$ & 65.6 & 39.7 & 33.9 & 22.1 & 5.6 & - \\
\hline
\end{tabular}

Living Condition

The number of persons per household and the total space of average sized houses will indicate an aspect of general living condition (Table 3).

a) The number of persons per household in 1955 was 5.0 in average, but it was reduced to 3.7 in 1980 .

b) The number of persons per one room was 2.2 in 1955, and was reduced to 0.9 in 1980 .

c) Average space available per household member was $4.1 \mathrm{~m}^{2}$ in 1955 but was increased to $9.7 \mathrm{~m}^{2}$ in 1980, an increase of over 200 percent.

d) Average floor space per house: In 1955 the average floor space of'a single house was $45 \mathrm{~m}^{2}$. In 1980 the index marked $95 \mathrm{~m}^{2}$ indicating the space available within a house was more than 
doubled in this period.

As seen above, over crowding in a residence has disappeared after 1970, possibly contributing to the apparent reduction of leprosy transmission among the household contacts.

Table 3. The Trend of Living Condition

\begin{tabular}{lrrrrrrr}
\hline & 1955 & 1960 & 1965 & 1970 & 1975 & 1980 \\
\hline No. of Person per Household & 5.0 & 4.6 & 4.5 & 4.3 & 4.0 & 3.7 \\
\hline No. of Person per One Room & 2.2 & 1.7 & 1.5 & 1.2 & 1.0 & 0.9 \\
\hline Space per Household & 4.1 & 4.1 & 4.9 & 6.4 & 8.4 & 9.7 \\
\hline Floor Space per House & 45 & 47 & 51 & 51 & 71 & 95 \\
\hline
\end{tabular}

Composition of Household

As the result of industrialization agricultural population was reduced considerably.

The recent trend in rapid industrialization and urbanization and urbanization has contributed to reduce agricultural population and the former large family system has given way to so called nucleus family and single member household. Nucleus families occupied $61.5 \%$ in 1965 but was increased to 65\% in 1975; single member household increased from $9.4 \%$ to 18.0\%. The reduction in the size of family members contributed to improve living conditions.

\section{LEPROSY IN RURAL AREA}

Formerly most leprosy cases were found in rural area. In 1955 83.3\% of the patients were from rural area. But recent trend shows less patients in rural area and in 1980 it was reduced to 31.68 indicating that leprosy in Okinawa is already becoming urban leprosy.

\section{Leprosy in Taiwan}

Taiwan with its population of 17 million is located not far to the south of Okinawa and also belongs to sub tropical climate. The leprosy control in that island was started in 1930 under the Japanese regime.

In 1960 the Government started out-patient treatment in an attempt to bring patients under a new leprosy control scheme. As the result, the incidence rate marked its peak of $0.33 / 100,000$ in 1962 (Figure 4), and by 1969 a majority of patients left in community were brought under control by out-patient chemotherapy treatment. This is very similar to the case of okinawa. The number of new patients gradually decreased after 1970.

GNP, National Income, private medical and health expenditure, 


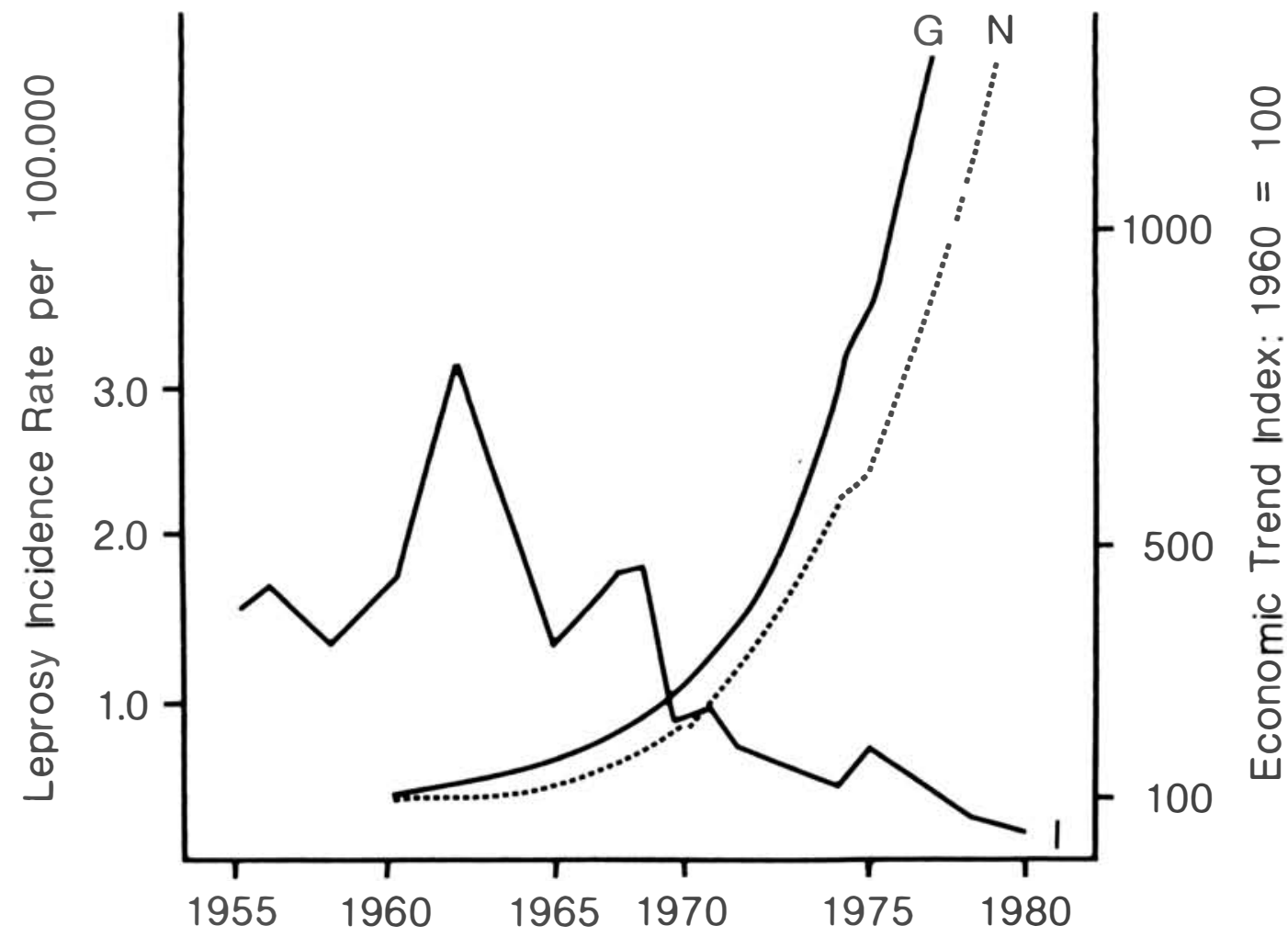

Figure 4. To show the relationship between trend of socioeconomic development and leprosy Incidence Rate in Taiwan. G:GNP, N:National Income, I:Leprosy Incidence Rate.

number of persons making the first visit to public hospitals are shown in Figure 4. A marked increase is observed between 1970 and 1975 and this coinsides with a marked decline in the incidence of leprosy which took place after 1970.

Socio-economic development of Taiwan brought forth improvements in standard of living, environmental sanitation, public hygiene and housing situation just as in Japan and Okinawa, which influenced greately the decline in the incidence of leprosy after 1970 .

\section{Conclusion}

In Japan possibility of leprosy transmissions in the community appeared to have been successfully minimized by rather strict segregation policy started 50 years ago backed by the huge budgetary allocation by the national government. This whole process took 
place before Japan achieved rapid economic growth and also before the start of chemotherapy treatment. Okinawa and Taiwan, on the contrary, achieved reduction of incidence of leprosy after the start of chemotherapy treatment, mostly on out-patient basis, and also at the time of rapid socio-economic improvements.

Rapid socio-economic development brought improvements in standard of living and social environment, particularly of housing situation. These, together with decrease in the size of family, greatly contributed toward removing overcrowded living situation. As the result, the chances of household contact in rural area, where the prevalence rate was high, was reduced, which in turn possibly contributed considerably to reduce the number of new leprosy patients.

In summary, it may be reasonable to assume when there is an active leprosy control program to prevent the infection in the community, socio-economic development makes notable contribution to reduce chances of infection, thus reducing leprosy in community. 